\title{
Experimental Study on Thermal Hydraulic Performance of Plate-Type Heat Exchanger Applied in Engine Waste Heat Recovery
}

\author{
Dong Junqi ${ }^{1}$ - Zhang Xianhui $^{2}$ - Wang Jianzhang ${ }^{1}$
}

Received: 19 October 2016 / Accepted: 27 July 2017 / Published online: 8 August 2017

(C) The Author(s) 2017. This article is an open access publication

\begin{abstract}
This paper experimentally investigates the thermal hydraulic characteristics for three types of fluid on plate heat exchanger surfaces. The three types of fluid are R245fa, glycol and water. The characteristics of heat transfer coefficient $N u$ and friction factor $f$ are given. The concept of pump power is provided to overall evaluate the enhanced heat transfer. The dimensionless correlation equations of $\mathrm{Nu}$ and $f$ factors are provided using multiple regression method. The mean absolute errors for the $N u$ and $f$ factor are 9.7 and $6.8 \%$ in the whole test range.
\end{abstract}

Keywords Rankine cycle · Plate type $\cdot$ R245fa $\cdot$ Thermal hydraulic $\cdot$ Empirical formula

\section{List of symbols}

$\begin{array}{ll}A & \text { Area }\left(\mathrm{m}^{2}\right) \\ b & \text { Average gap }(\mathrm{mm}) \\ c_{\mathrm{p}} & \text { Specific heat capacity }(\mathrm{J} / \mathrm{kg} \mathrm{k}) \\ d & \text { Diameter of inlet and outlet pipe }(\mathrm{m}) \\ d_{\mathrm{h}} & \text { Hydraulic diameter }(\mathrm{mm}) \\ E_{\mathrm{m}} & \text { Mean error } \\ E_{\mathrm{ab}, \mathrm{m}} & \text { Absolute mean error }\end{array}$

Dong Junqi

dongjunqi2008@163.com

Zhang Xianhui

xianhuizhang@163.com

Wang Jianzhang

wangjianzhang2012@163.com

1 Thermal Management Research Institute, Zhejiang Yinlun Company, Zhejiang, China

2 School of Foreign Languages, Qingdao University of Science and Technology, Qingdao, Shandong, China

$\begin{array}{ll}f & \text { Friction factor } \\ h & \text { Heat transfer coefficient }\left(\mathrm{W} / \mathrm{m}^{2} \mathrm{~K}\right) \\ L & \text { Flow length }(\mathrm{m}) \\ m & \text { Mass flow rate }(\mathrm{kg} / \mathrm{s}) \\ n & \text { Total number of test data } \\ \Delta P & \text { Pressure drop }(\mathrm{Pa}) \\ P r & \text { Prandtl number } \\ Q & \text { Heat rejection power }(\mathrm{W}) \\ R e & \text { Reynolds number } \\ t & \text { Temperature }\left({ }^{\circ} \mathrm{C}\right) \\ U & \text { Total heat transfer coefficient }\left(\mathrm{W} / \mathrm{m}^{2} \mathrm{~K}\right) \\ U A & \text { Total heat transfer coefficient }(\mathrm{W} / \mathrm{K}) \\ u_{\mathrm{m}} & \text { Mean velocity }(\mathrm{m} / \mathrm{s}) \\ \Delta T_{\mathrm{LMT}} & \text { Log mean temperature difference }\left({ }^{\circ} \mathrm{C}\right) \\ v & \text { Viscosity }\left(\mathrm{m}^{2} / \mathrm{s}\right) \\ \lambda & \text { Thermal conductivity }(\mathrm{W} / \mathrm{m} \mathrm{K}) \\ \varphi & \text { Factor } \\ \beta & \text { Plate chevron angle }\left({ }^{\circ}\right) \\ \delta & \text { Plat thickness }(\mathrm{m}) \\ \eta & \text { Viscosity }(\mathrm{kg} / \mathrm{s} \mathrm{m}) \\ \rho & \text { Density }\left(\mathrm{kg} / \mathrm{m}^{3}\right)\end{array}$

\section{Subscripts}

1

2

$\mathrm{ab}$

ave

c

etd

$\exp$

h

in
Inlet port

Exit port

Absolute

Average

Cold side

Entrance temperature difference $\left({ }^{\circ} \mathrm{C}\right)$

Experiment

High temperature side

Inlet 


$\begin{array}{ll}\mathrm{i} & \text { Hot or cool side } \\ \mathrm{m} & \text { Mean } \\ \max & \text { Maximum } \\ \min & \text { Minimum } \\ \text { out } & \text { Exit port or outlet pipe } \\ \text { pre } & \text { Predicted } \\ \mathrm{p} & \text { Pipe }\end{array}$

\section{Introduction}

Organic Rankine cycle (ORC) is treated as a very useful technology in waste heat recovery field [1-3]. Comparing to thermal power generation which is based on Rankine cycle, the Rankine cycle applies organic fluid as the working media which can absorb lower temperature heat source without too much working pressure.

It is well known that the diesel efficiency is only about $40 \%$ in the past 20 years, and there is above $50 \%$ energy emitted to environment [4]. As for the fuel efficiency improvement requirement, more and more studies had been done about how to improve the efficiency. These waste heat resources include the cylinder glycol (about the $90-105^{\circ} \mathrm{C}$ ) and diesel exhaust gas $\left(250-450^{\circ} \mathrm{C}\right)$. The conventional method for high-power engine waste heat recovery uses the coolant as the heat energy transfer media, which can reduce the waste heat recovery system complexity and total cost $[5,6]$.

In the ORC system, the plate types of heat exchanger are widely used, the evaporator and the condenser. And the PHE's can much reduce the organic working fluid charge as for the smaller volume. So the running cost of the ORC system can be cut down. The enhanced heat transfer mechanism mainly depends on the complex channel geometry, in which the fluid will have a bigger turbulence of the flow. Up to now, the PHE's heat transfer characteristics for the single phase were studied by many studiers [7-9]. For example, the Longo and Gasparella [10] developed the Nusselt number equations. Muley [11] investigated thermo-hydraulic characteristics of PHE with mixed chevron angles. However, the most previous studies are lack of the detail introduction, such as the test conditions and plate geometry structure.

And it is clear to see, the working conditions of PHE's in Rankine cycle system have much difference comparing to traditional application. First, the working fluids are different in the diesel waste heat recovery system. In the diesel WHR system, the glycol, water and R245fa are used. The glycol is used as intermediate media which are used to absorb all the engine waste heat. The refrigerator fluid R245fa is used in the ORC system, and the water is used as the cool side fluid of ORC condenser. And it is very hard to get the thermal hydraulic performance from those public literatures. The most obvious difference is that the R245fa velocity is much smaller than that of water or glycol. The R245fa flow velocity in the PHE's channel is very smaller than the others fluids. The R245fa thermal hydraulic performance character will have much different with those of the ordinary fluid which have higher velocity in the flow pass or channel. However, there are very little the test data or empirical formulas in public paper.

The aim of this study work is providing PHE's thermal hydraulic characteristics for the three types of working fluid including the water, glycol and R245fa which are widely used in diesel waste heat recovery. And the paper will provide the test empirical equations to predict the thermal hydraulic performance which are most useful for the engineers.

\section{Test Rig and Experiment Procedures}

\subsection{Waste Heat Recovery Introduction}

In the diesel waste heat recovery system, there are two parts of waste heat source. Figure 1 shows the waste energy conversion and utilization principle based on the ORC mechanism. From Fig. 1, it can be seen that the glycol first absorbs the cylinder waste heat of engine, then it absorbs the energy from the high temperature exhaust gas. In the waste heat transfer process, the glycol is used as the intermediate media, which is used to transfer the waste heat to working fluid R245fa in ORC. R245fa with a higher pressure can absorb the diesel waste heat in the preheater $\mathrm{E}$ and evaporator $\mathrm{D}$.

As for the compactness and lower refrigerator charge, the plate-type heat exchangers are used as preheaters, evaporators and condensers in the WHR. The heat transfer fluids are the glycol, water and R245fa.

\subsection{Test Rigs}

The main aim of this study is provide the thermal hydraulic performance for the three types of working fluid on three different PHE's heat transfer surfaces. This test investigates the water heat transfer and flow resistance character under different flow velocity. This is the test data reduction base which uses the thermal resistance separation. The main parts are the experimental study on the thermal hydraulic performance for the three types of fluid on the PHE's surface. In Table 1, all sensors test accuracies are listed

In Fig. 2, the water is used as the cool and high temperature fluid of PHE's two sides. In the test system, water is the only fluid in the loop and one flow meter is used. As for the property of water has not obvious change in a smaller temperature range, the water is selected as working media. And the water heat transfer coefficients on the surface are much bigger than those of other fluid under the same flow velocity. During the test process, to keep two sides water flow 
Fig. 1 Test rig of waste heat recovery a ORC system mechanism, b diesel generator ORC test rig photograph

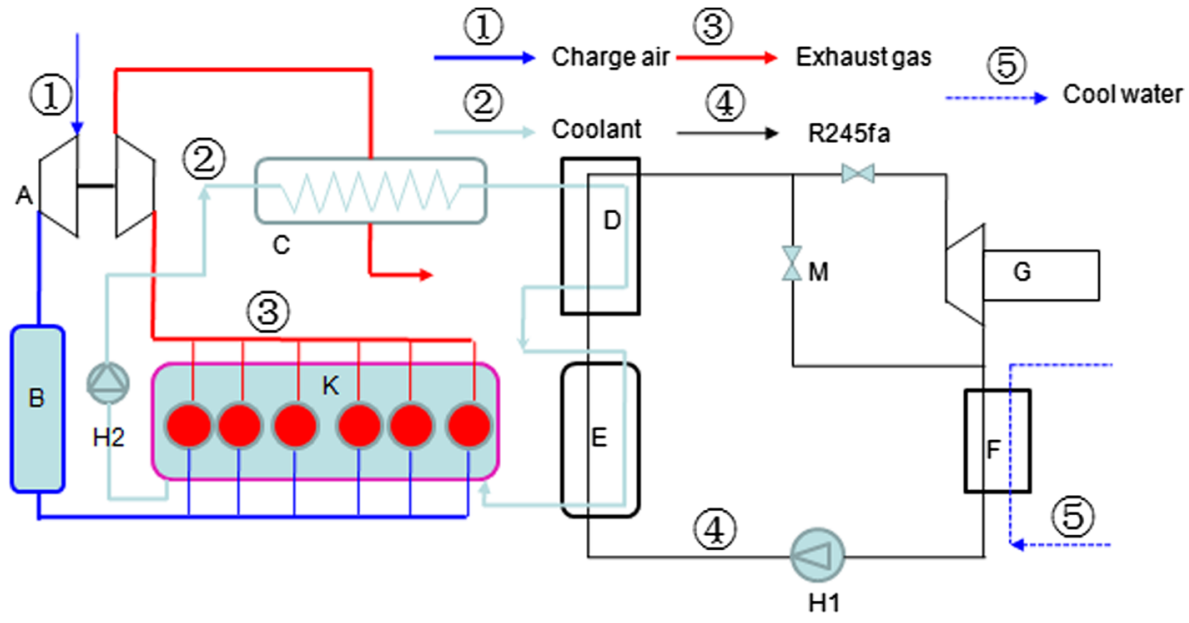

A: Exhaust gas turbine compressor

$B$ : Charge air cooler

$\mathrm{C}$ : Exhaust Heat exchanger

D: Plate type evaporator

E: Plate type pre-heater

F: Plate type condenser

G: Expander and Generator

H1: R245fa Pump

$\mathrm{H}$ 2: coolant pump

$\mathrm{K}$ : Diesel engine

$\mathrm{M}$ : By pass valve

(a)

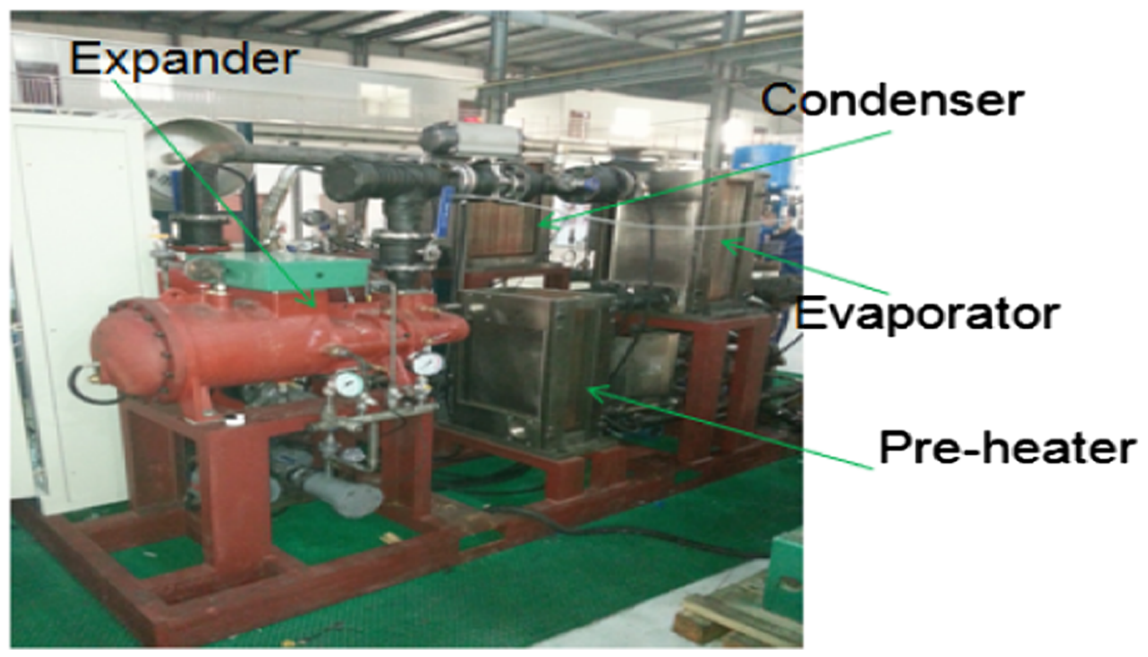

(b)

Table 1 Specification for the sensor accuracies

\begin{tabular}{lllll}
\hline Devices & Type & Uncertainty $(k=2)$ & Range & Application \\
\hline Temperature & RTD100 & $0.1 \mathrm{k}$ & $0-120^{\circ} \mathrm{C}$ & Water, glycol, R245fa \\
Pressure abs. & Strain-gage & $0.075 \%$ & $0-0.6 \mathrm{MPa}$ & Water coolant \\
Pressure abs. & Strain-gage & $0.075 \%$ & $0-1.2 \mathrm{MPa}$ & $\mathrm{R} 245 \mathrm{fa}$ \\
Diff. pressure transducer & Strain-gage & $0.075 \%$ & $0-100 \mathrm{kpa}$ & Water and glycol \\
Diff. pressure transducer & Strain-gage & $0.075 \%$ & $0-10 \mathrm{kpa}$ & $\mathrm{R} 245 \mathrm{fa}$ \\
Mass flow meters & Coriolis effect & $0.1 \%$ & $0-2000 \mathrm{~kg} / \mathrm{h}$ & $\mathrm{R} 245 \mathrm{fa}$ \\
Mass flow meters & Coriolis effect & $0.1 \%$ & $0-15,000 \mathrm{~kg} / \mathrm{h}$ & Water, glycol \\
\hline
\end{tabular}

at the approximate equal average $R e$, two side fluids flow in the counter flow and the average temperature difference of two sides should be less than $5^{\circ} \mathrm{C}$.
Figure 3 simply describes the water and coolant test rig. The glycol is used in the high temperature side with an electric heater which is about $80 \mathrm{~kW}$. The water is used as 
Fig. 2 PHE's test rig for water

Test Plate

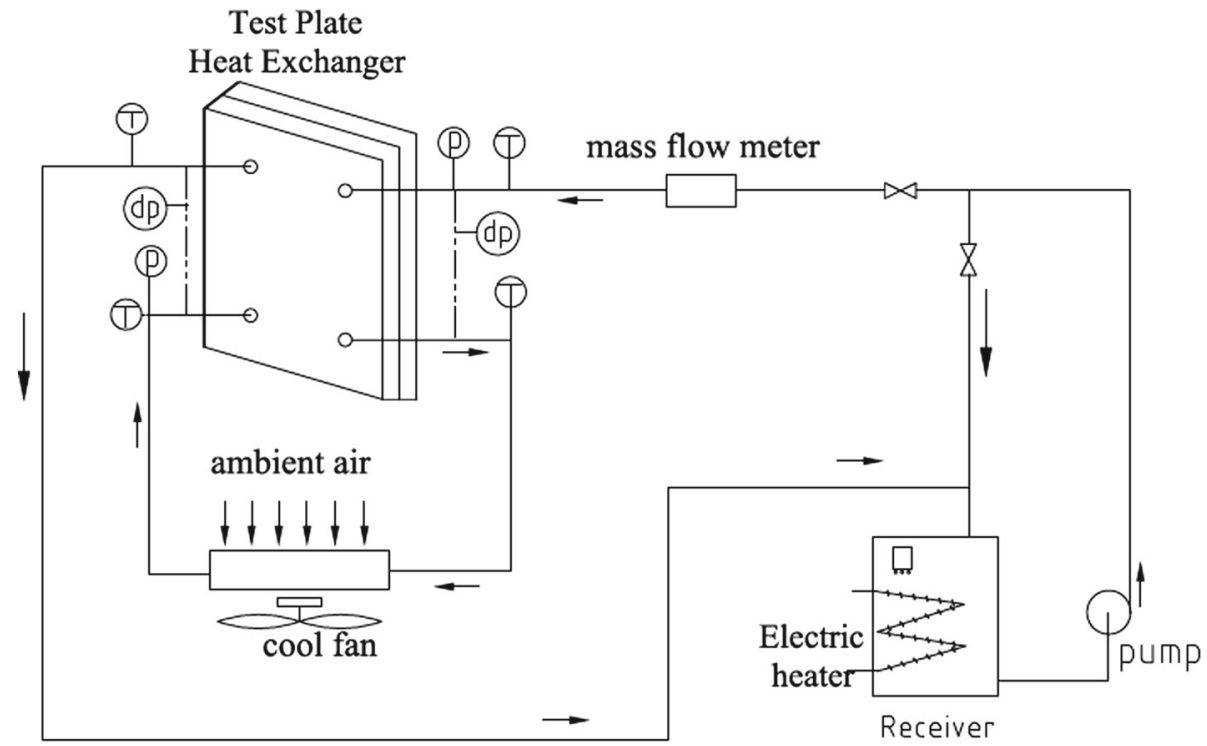

(1) temperature sensor

(D) pressure sensor

(dP) pressure difference sensor

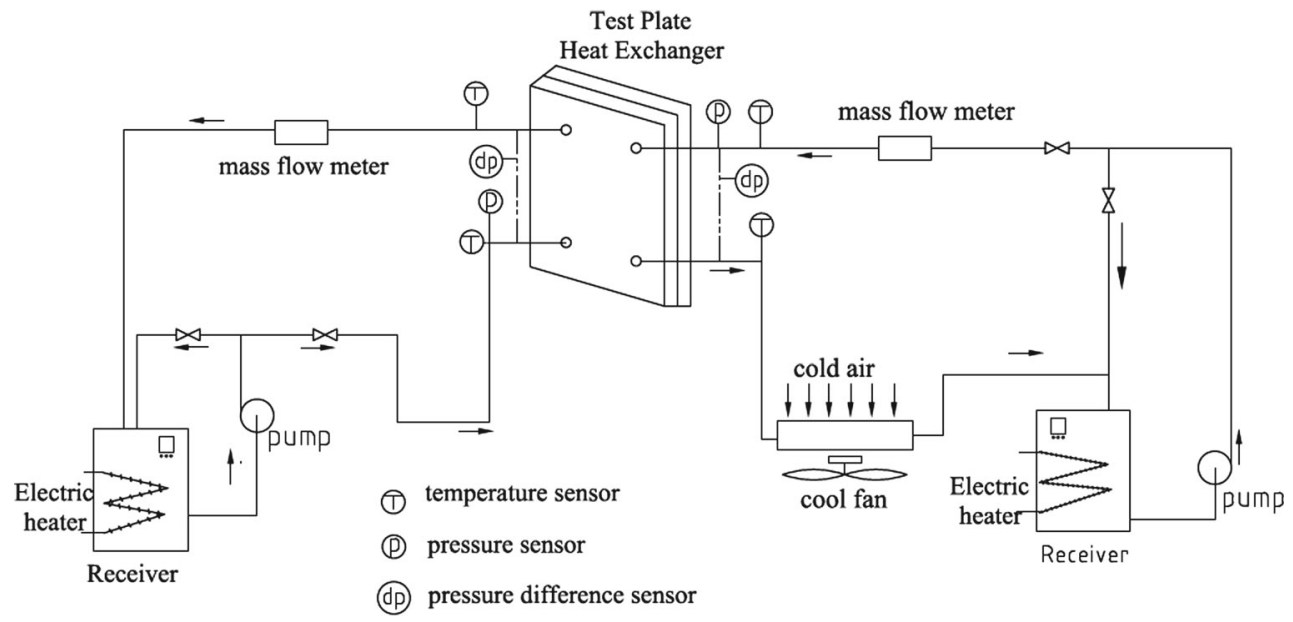

Single phase liquid test system

Fig. 3 Water and glycol test rig

cool fluid, in which the inlet temperature of the test sample can be adjusted. The two mass flow meters are used and recorded. The inlet and outlet temperatures and pressure of the test sample are recorded by temperature and pressure sensors. In Fig. 4, we can see the test mechanism. About the detail introduction for the test rigs and test procedure can be found in the authors' previous paper [12].

\subsection{Plate-Type Heat Exchanger Test Samples}

The test samples with different chevron plates are tested. For the chevron plate-type heat exchanger, the detail geometric parameters definition are shown in Table 2 and Fig. 5. In Fig. 5, the real plate surface is shown for the testing sample and cut surface of the middle section. These parameters include the plate chevron angle, corrugation depth and corrugation pitches. There are three different chevron 


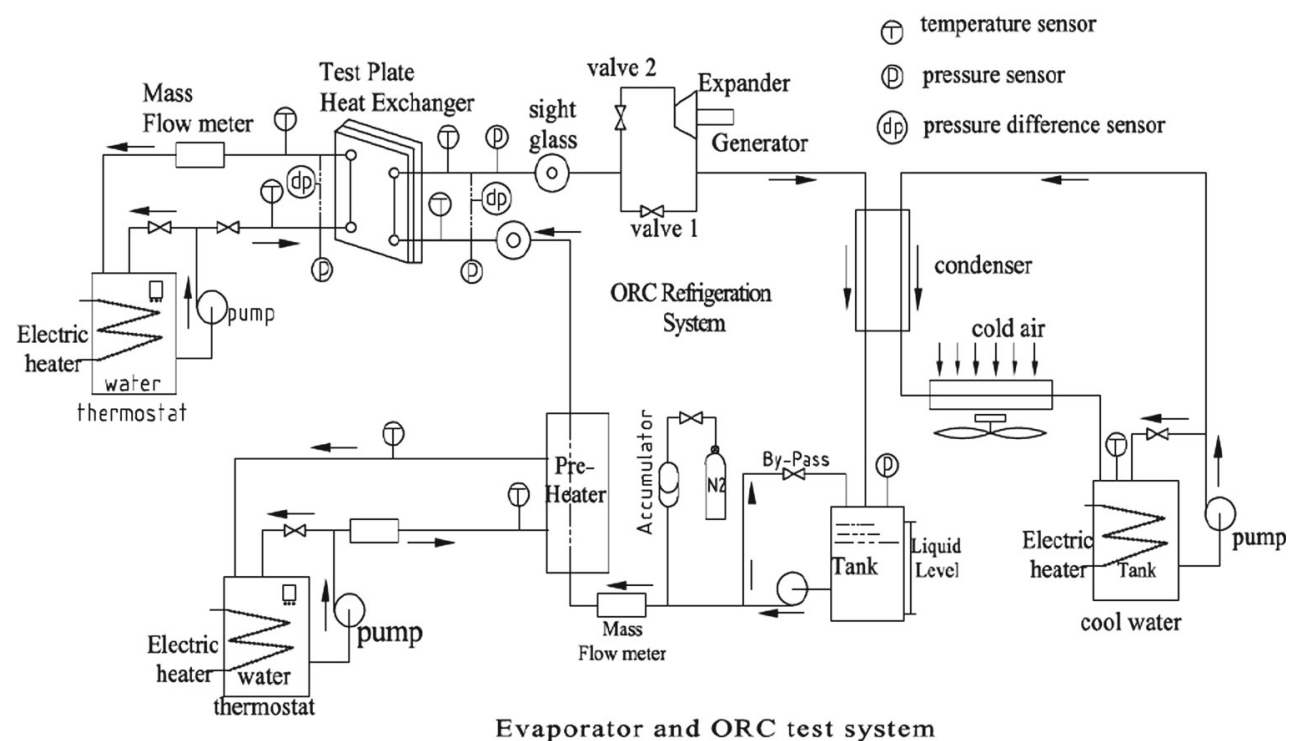

Fig. 4 Refrigerator R245fa test rig

Table 2 PHE plate structure parameters

\begin{tabular}{ll}
\hline Lw, plate width $(\mathrm{mm})$ & 310 \\
Lp, plate port-to-port channel length $(\mathrm{mm})$ & 624 \\
$L_{\text {eff }}$, plate effective channel length $(\mathrm{mm})$ & 544 \\
Dp, diameter (mm) & 40 \\
b, mean flow channel gap (mm) & 2.35 \\
$\delta$, plate thickness (mm) & 0.3 \\
$p_{\mathrm{c}}$ : corrugation pitch (mm) & 8 \\
$\varphi$, enlargement factor & 1.16 \\
$\beta$; plate chevron angle & $60^{\circ}, 60^{\circ} / 30^{\circ}, 30^{\circ}$ \\
\hline
\end{tabular}

angles, including $60^{\circ}, 60^{\circ} / 30^{\circ}, 30^{\circ}$. The mixed chevron angle $60^{\circ} / 30^{\circ}$ is treated as the average $45^{\circ}$. Each sample has one pass with ten channels, and the two side fluids are counter flow in the test process.

\subsection{Data Reduction Testing Uncertainty}

The dimensionless parameters, such as the Reynolds number $R e$, heat transfer coefficient $h$, the Nusselt number $N u$ and the friction factor $f$, are widely used in the heat exchanger calculation and analysis. Their definitions are listed as follows:

$$
\begin{aligned}
R e & =\frac{u_{\mathrm{m}} \cdot d_{\mathrm{h}}}{v} \\
N u & =\frac{h \cdot d_{\mathrm{h}}}{\lambda} \\
f & =\frac{2 \cdot \Delta p \cdot d_{\mathrm{h}}}{\rho \cdot L \cdot u_{\mathrm{m}}^{2}}
\end{aligned}
$$

To obtain the heat transfer coefficient and friction factor of PHE's surface, the thermal resistance separation methods are applied. The heat transfer coefficient is obtained for the water, glycol and R245fa using the different data reduction. For water, the data reduction adopts the equal $R e$ method. For the coolant and R245fa, the thermal resistance separating method is applied based on the first step, in which the heat transfer coefficients of waterside are known.

According to the thermal resistance separation mechanism, the overall heat transfer coefficient UA in the heat exchanger can be expressed,

$$
\frac{1}{\mathrm{UA}}=\frac{1}{h_{\mathrm{c}} \cdot A}+\frac{1}{h_{\mathrm{h}} \cdot A}+\frac{\delta}{\lambda \cdot A}
$$

The detail reduction method for the thermal resistance separation methods can be seen in the literature [12].

The friction factor $f$ is used to evaluate the fluid flow resistance or pressure drop in the channel. The testing pressure drop $\Delta P_{\text {exp }}$ includes five parts [13], inlet local pressure loss $\Delta P_{\text {in }}$ (deceleration), inlet pipe friction pressure loss $\Delta P_{\text {in }-\mathrm{p}}$, outlet local pressure loss $\Delta P_{\text {out }}$ (acceleration), outlet pipe friction pressure loss $\Delta P_{\text {out }-\mathrm{p}}$ and the friction pressure loss 


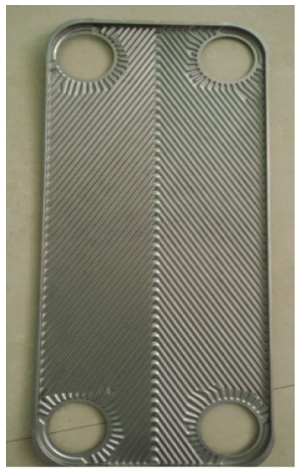

(a)

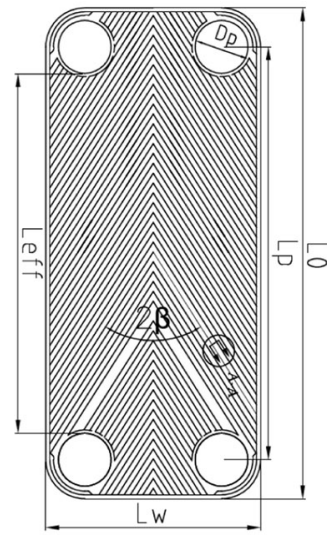

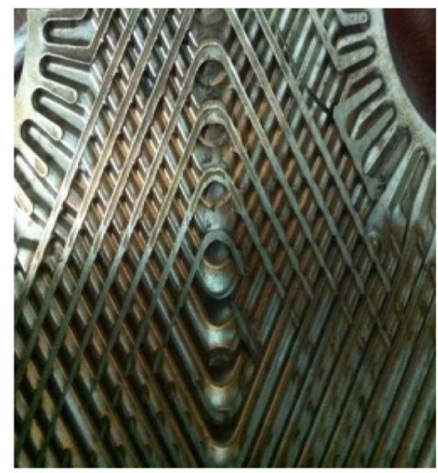

(b)

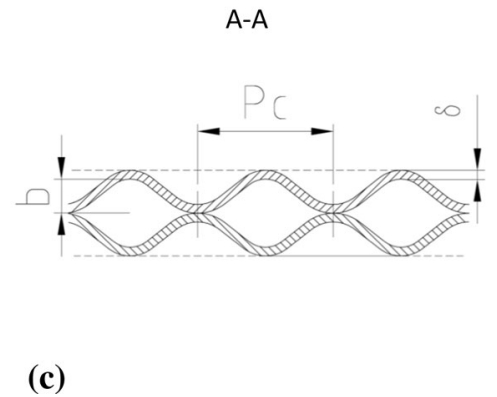

Fig. 5 PHE geometry parameters a plate photograph $\mathbf{b}$ cut surface for the middle section of PHE $\mathbf{c}$ definition for PHE parameters

of the corrugation channel $\Delta P$.

$$
\begin{aligned}
\Delta p_{\text {exp }} & =\Delta p_{\text {in }-\mathrm{p}}-\Delta p_{\text {in }}+\Delta p+\Delta p_{\text {out }}+\Delta_{\text {out }-\mathrm{p}} \\
\Delta p_{\text {in }} & =\frac{1}{2} \cdot \rho \cdot u_{\mathrm{m}}^{2} \\
\Delta p_{\text {out }} & =\frac{1}{2} \cdot \rho \cdot u_{\mathrm{m}}^{2}
\end{aligned}
$$

In Eq. (5), the local pressure loss of the inlet $\Delta P_{\text {in }}$ and outlet $\Delta P_{\text {out }}$ is almost equal. The core pressure drop $\Delta P$ is:

$$
\begin{aligned}
\Delta p & =\Delta p_{\text {exp }}-\Delta p_{\text {in }-\mathrm{p}}-\Delta_{\text {out }-\mathrm{p}} \\
\Delta p_{\text {in }-\mathrm{p}} & =\frac{1}{2} \cdot f_{\mathrm{p}} \frac{L}{d} \cdot \rho \cdot u_{\text {in }-\mathrm{p}}^{2} \\
\Delta p_{\text {out }-\mathrm{p}} & =\frac{1}{2} \cdot f_{\mathrm{p}} \frac{L}{d} \cdot \rho \cdot u_{\text {out }-\mathrm{p}}^{2} \\
f_{\mathrm{p}} & =\left[1.82 \cdot \log _{10} R e_{\mathrm{p}}-1.64\right]^{-2}
\end{aligned}
$$

In Eqs. (6-11), the $u_{\mathrm{m}}$ is the average velocity in the flow channel, $u_{\text {in-p }}$ and $u_{\text {out }-\mathrm{p}}$ are the average flow velocity in the inlet connect pipe and outlet connect pipe of test sample. $f_{\mathrm{p}}$ is the friction factor of connect pipe, $L$ is the connect tube length.
According to Eq. (12), it is easy to get the pressure drop of the channel $\Delta p$, and the fraction factor $f$ can be obtained [14]:

$$
f=\frac{2 \cdot \Delta p \cdot d_{\mathrm{h}}}{\rho \cdot L_{\mathrm{p}} \cdot u_{\mathrm{m}}^{2}}
$$

According to the Moffat [15] proposed a procedure outline and formula to evaluate the uncertainty, the maximum errors in the primary measurement of mass flow rate and temperature are found to be \pm 2.1 and $\pm 1.2 \%$, respectively. Based on these errors, the maximum uncertainty of $\pm 8.2 \%$ exists in calculated value of $\mathrm{Nu}$. And the maximum uncertainty of factor $f$ is $\pm 9.6 \%$.

\section{Results, Discussion and Analysis}

\subsection{Thermal Characters}

The testing results about the heat transfer performance are described and discussed. For the single phase fluid, the velocity and geometry parameters are the most important factors on the plate-type surface heat transfer characteristics. Figure 6 describes the changing curves of the heat transfer coefficients under the different fluid velocity. From Fig. 6, you can see that the fluid velocity and plate chevron angle $\beta$ have the most obvious effects on heat transfer performance. The heat transfer coefficients will increase with the velocity and the chevron angle $\beta$ increasing. For heat transfer performance, that of the chevron angle $\beta=60^{\circ}$ are bigger than the $\beta=30^{\circ}$ and $\beta=45^{\circ}$ under the same fluid velocity. At the same time, we can see that the enhanced heat transfer effects of chevron angle $\beta$ are not obvious in the R245fa test results. In Fig. 6c, it describes the effects of three chevron angles on the heat transfer coefficients under different velocity.

At the same time, the $R e$ and $N u$ are used to describe the heat transfer performance. Figure 7 shows the heat transfer performance of three different fluids with different $R e$ and different chevron angles $\beta$. In Fig. 7c about the trend of $N u$ with $R e$ for the R245fa fluid, it can be clear to see that there is no particular increase for the $N u$ with the chevron angle increasing under the same $R e$. This heat transfer performance curve has much difference with coolant and water under high $R e$ region. The reason is that the flow condition of $\mathrm{R} 245 \mathrm{fa}$ is in lower Re region. In the lower Re region, the turbulence of fluid flow becomes smaller.

In Fig. 8, we can see that the increasing rate of heat transfer coefficients has much difference for the three different types of working fluid. The water and glycol have the similar change trend. With the Re increasing, the heat transfer coefficients quickly increase. However, under the same $R e$, the heat transfer coefficients of R245fa are much lower than 


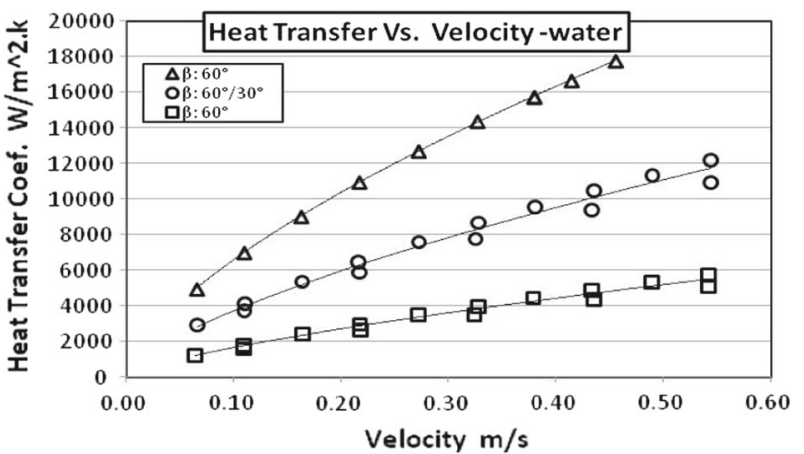

(a)

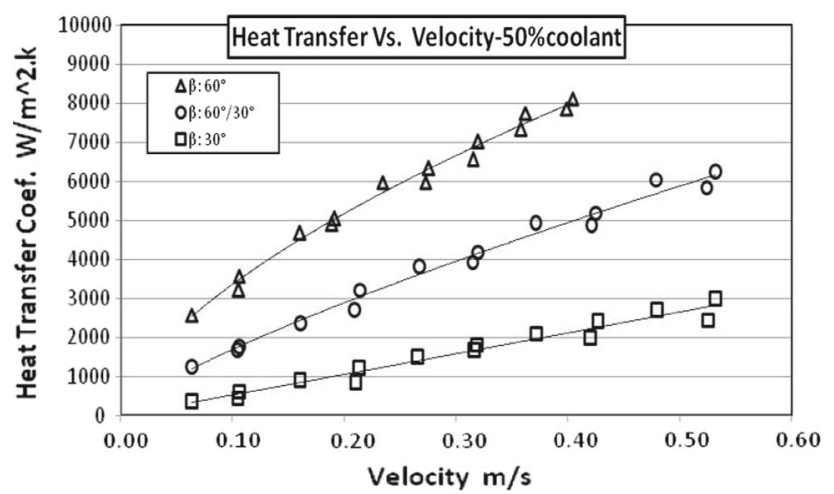

(b)

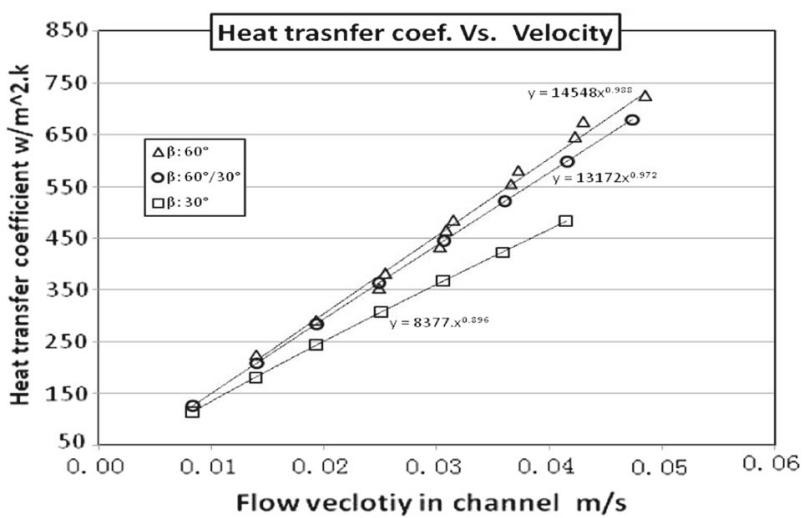

(c)

Fig. 6 Heat transfer characters for different flow velocity a water $\mathbf{b}$ glycol c R245fa

those of the water and glycol. From the viewpoint of heat transfer coefficient change rate, $\mathrm{R} 245 \mathrm{fa}$ has a very much bigger change rate under the low $R e$ region, the increasing rate almost equals to 1 . The reasons may lie in the fact that $R 245 \mathrm{fa}$ has much difference in physical property parameters such as the viscosity, density, thermal conductivity and $P r$.

\subsection{Flow Resistance Characters for Three Types of Plate Structure}

The pressure drop and friction factor are used to describe the flow resistance of three types of fluid on the different

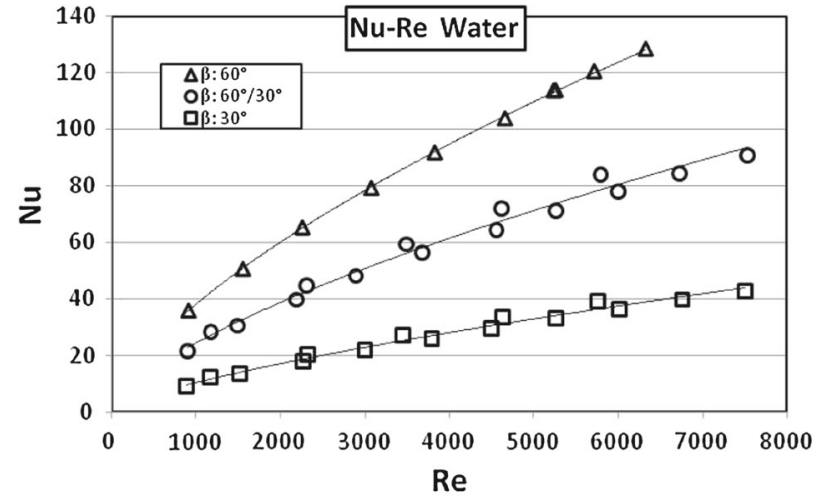

(a)

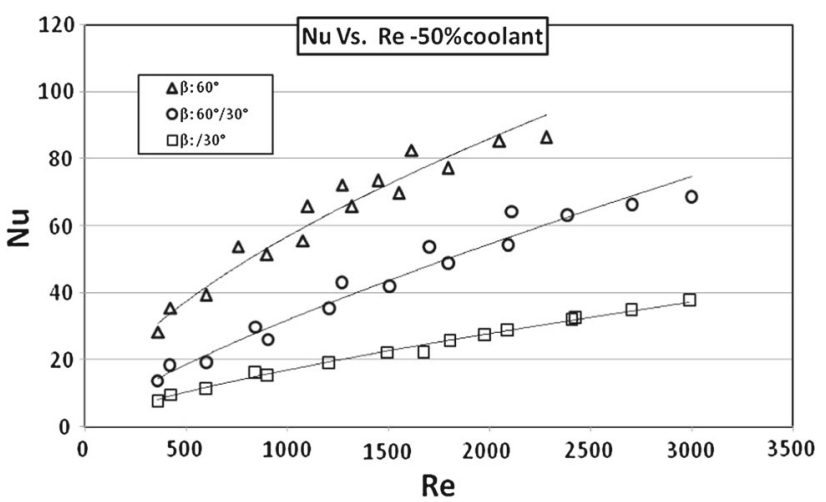

(b)

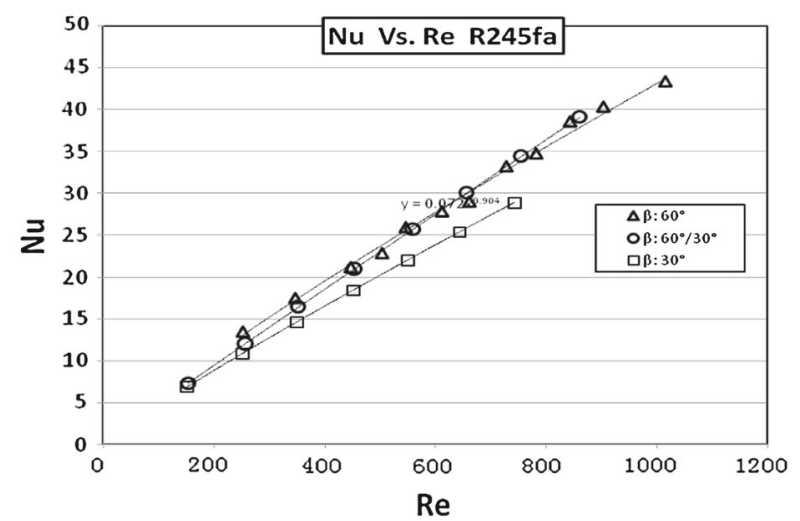

(c)

Fig. $7 \mathrm{Nu}-\mathrm{Re}$ a water, b glycol, c R245fa

chevron angle PHE's surface. Figure 9 describes the pressure drop curve with flow rate. Form the picture, it can be clearly seen that the pressure drop will increase with the chevron angle increasing. And the three types of fluid have the same variation characters. For $50 \%$ coolant and water, the pressure drop of chevron angle $\beta=60^{\circ}$ surface is much bigger than that of the chevron angle $\beta=30^{\circ}$ and $\beta=60^{\circ} / 30^{\circ}$. Figure 10 gives the flow resistance vibration character using the dimensionless parameters friction factor $f$ with $R e$. From the picture, the biggest friction factor $f$ is always been found in the chevron angle $\beta=60^{\circ}$ surface under the same Re. But, 


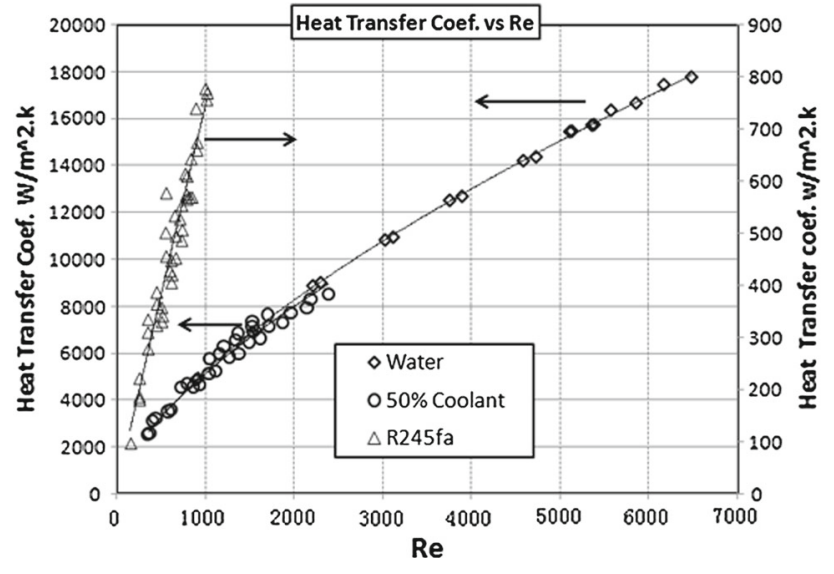

Fig. 8 Heat transfer character with $R e$ with $\beta=60^{\circ} / 30^{\circ}$

the difference of friction factor $f$ will become smaller for the chevron angle $\beta=30^{\circ}$ and $\beta=60^{\circ} / 30^{\circ}$ under the same Re. Also comparing the three pictures of the Fig. 10, it also can be seen that friction factor $f$ with fluid R245fa is bigger than that of the other two fluid under the same $R e$ and same chevron angle. The difference is brought about by the physical property difference of three types of fluid. The detailed explanation may need the CFD simulation or special flow test to describe the flow character in the PHE's complexcorrugated channel. This work will be done in the authors' future working plan.

\subsection{Thermal Hydraulic Performance Comparison}

To evaluate overall performance of the PHE's enhanced heat transfer surface, it would be necessary to consider heat transfer and pressure drop at the same time. The concept of pump power is introduced which is defined as follows [16],

Pump power $=$ Volume rate of fluid, $\mathrm{m}^{3} / \mathrm{s}$

$$
\times \text { Pressure drop, } \Delta p
$$

In Fig. 11 the heat transfers coefficient of three types of PHE's surface are compared with respect to the pump power. An overall inspection of Fig. 11 reveals that at the fixed pump power, a better heat transfer coefficients $h$ are found for the surface with chevron angle $60^{\circ}$. So the authors suggest the PHE's surface with chevron angle $60^{\circ}$ is a better choice when the engineer do the PHE's design. Of course, the chevron angle $60^{\circ} / 30^{\circ}$ is also suggested when the pressure drop has a strict limit.

\subsection{Empirical Correlation for the Single Phase Heat Transfer}

To expand the real industry application of the plate heat exchangers in the diesel engine waste heat recovery, the

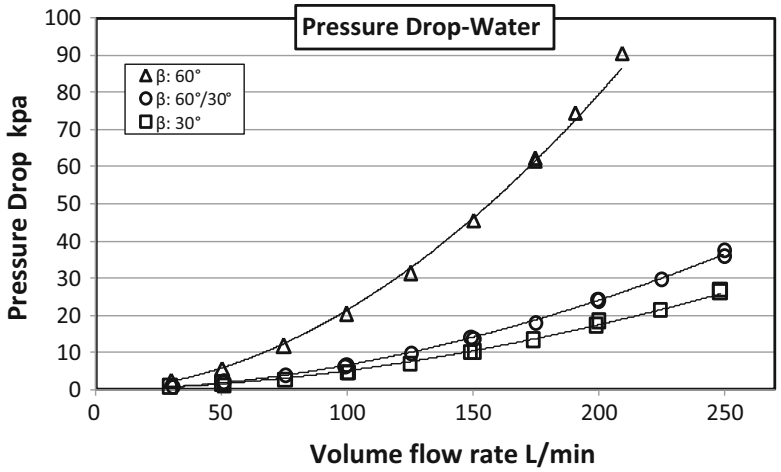

(a)

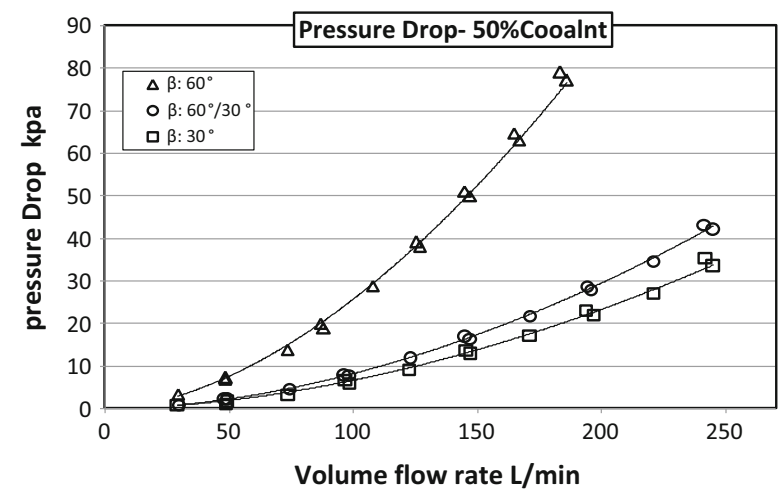

(b)

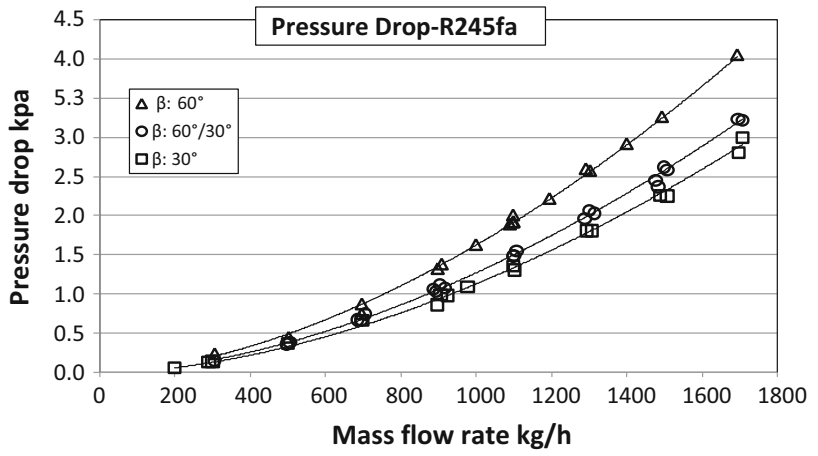

(c)

Fig. 9 Pressure drop with flow rate, a water, b 50\% coolant, c R245fa

empirical correlation for thermal hydraulic performance using the no-dimension format is provided. Using the multiple regression method, the empirical correlation is gotten based on all the test data. For the three working fluid and three different chevron angle plate heat exchangers, the heat transfer empirical correlation is:

$N u=0.964 \bullet \operatorname{Re}^{0.671} \bullet \operatorname{Pr}^{0.32}\left(\frac{\beta}{180}\right)^{1.022}$

The empirical correlation can predict $90 \%$ test data with the errors within $\pm 15 \%$. The detail comparison for the prediction $N u$ using the regression equation (13) and the test data 


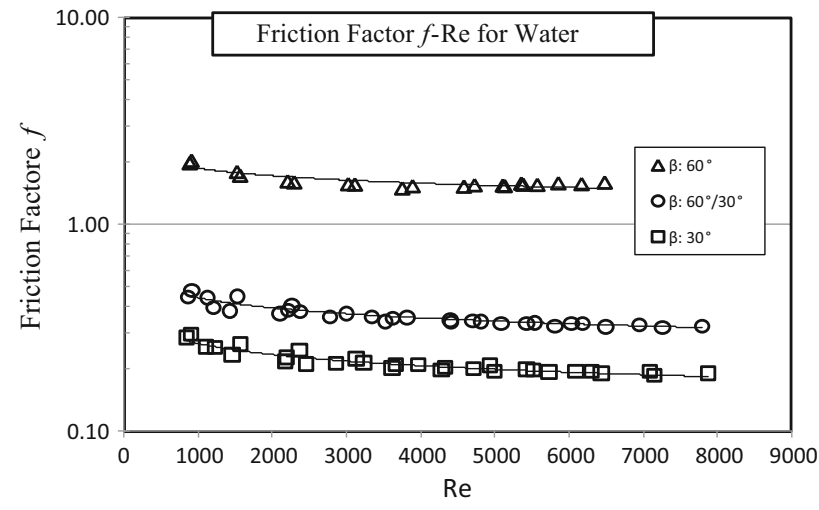

(a)

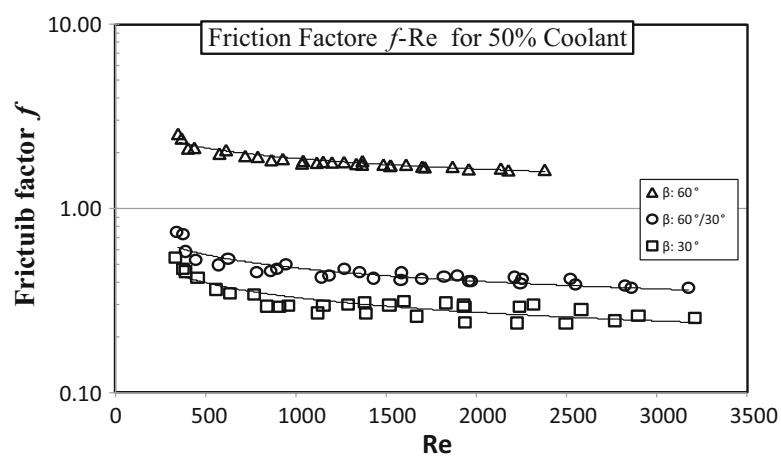

(b)

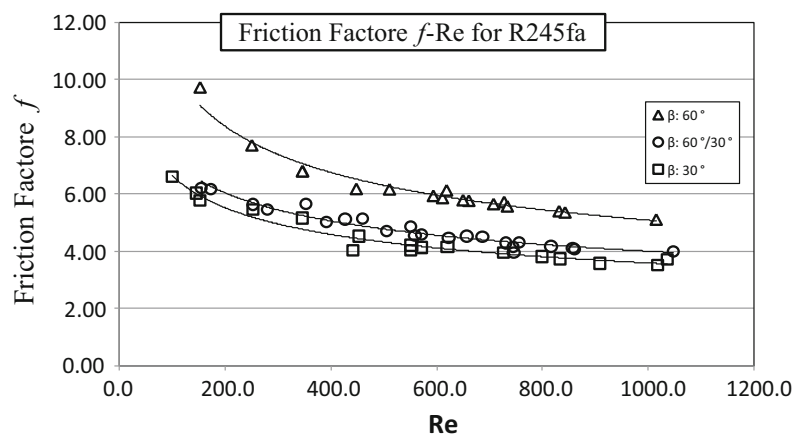

(c)

Fig. 10 Friction factor $\mathrm{f}$ with $R e$, a water, b 50\% coolant, c R245fa

is described in Fig. 12. The empirical correlation application must be strict in the range $R e=200-7000$ and $P r=2.0-$ 12.0. To make the users more understand the calculation accuracy and expand the application in the real PHE development, the calculation equation for the mean error and mean absolute errors [7] is given:

Mean error : $E_{\mathrm{m}}$

$$
=\frac{1}{n} \sum\left(\frac{N u_{\text {pre }}-N u_{\exp }}{N u_{\exp }}\right)
$$

Mean absolute error : $E_{\mathrm{m} . \mathrm{ab}}$

$$
=\frac{1}{n} \sum\left(\left|\frac{N u_{\mathrm{pre}}-N u_{\mathrm{exp}}}{N u_{\mathrm{exp}}}\right|\right)
$$

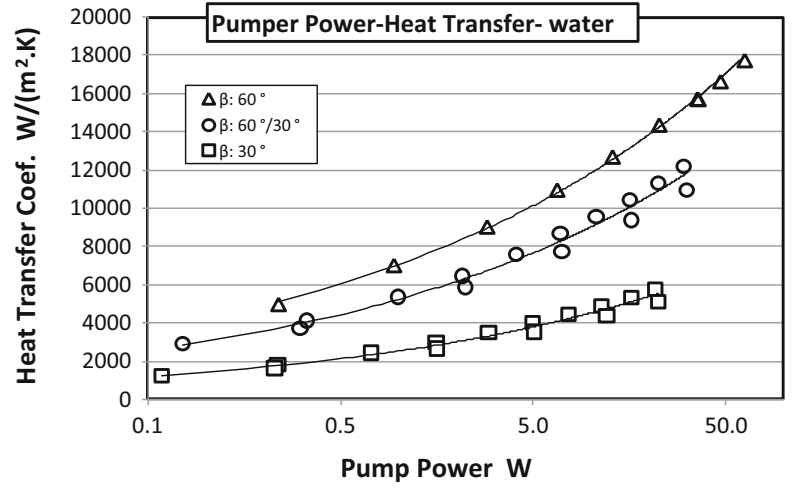

(a)

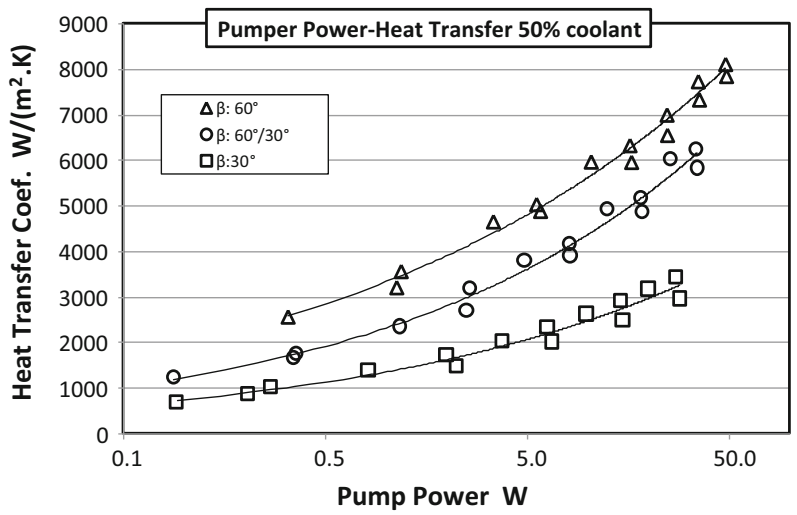

(b)

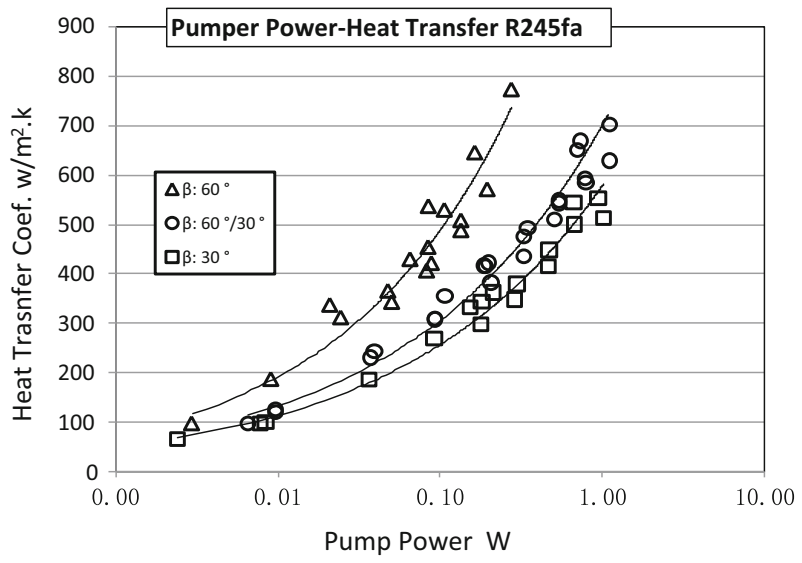

(c)

Fig. 11 Comparisons of heat transfer with pump power, a water, b $50 \%$ coolant, c R245fa

For the empirical correlation (13), the average error of this equation is $-1.7 \%$, mean absolute error is $9.7 \%$ for all the data.

As for there are much difference for the three types of fluid, two independent $f$ factor correlation equations are provided, respectively. Equation (16) is for water and 50\% coolant, Eq. (17) is for liquid R245fa.

For $50 \%$ coolant and water, the friction factor $f$ correlation equation is, 


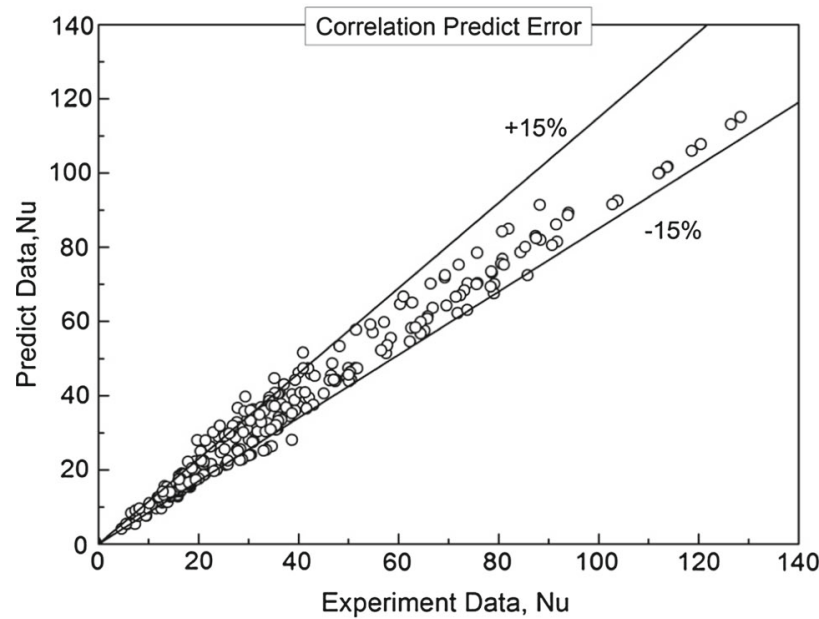

(a)

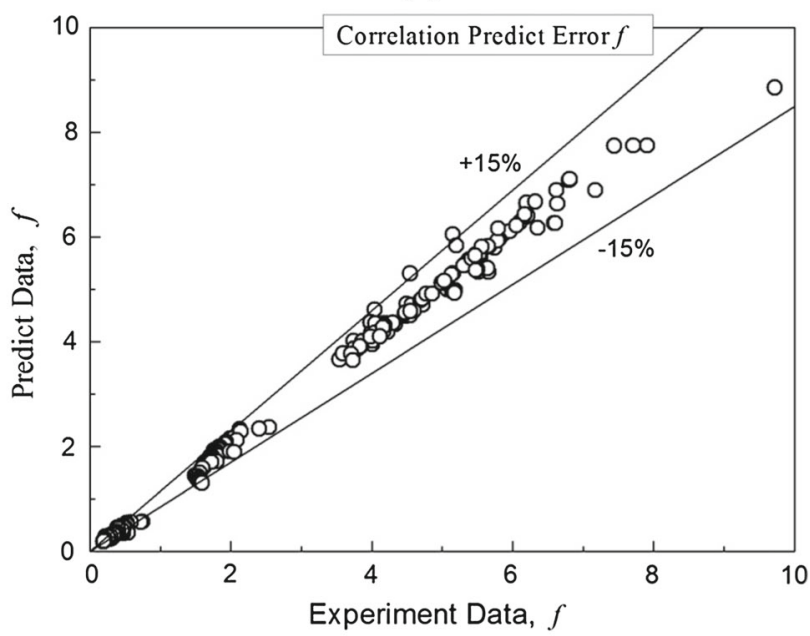

(b)

Fig. 12 Comparisons of the predicted data with test data, a heat transfer $N u, \mathbf{b}$ friction factor $f$

$f=0.158 \bullet \operatorname{Re}^{-0.189} \operatorname{Pr}^{0.031}(\sin \beta)^{-1.642}(\cos \beta)^{5.076}$

Using Eq. (16) to predict the test data, in the range $R e=400$ 7000 , the mean absolute error is $6.8 \%$ and the mean error is $0.3 \%$;

For organic fluid R245fa, the friction factor correlation equation is,

$f=14.67 \bullet \operatorname{Re}^{-0.27} \operatorname{Pr}^{0.054}(\sin \beta)^{-0.357}(\cos \beta)^{-1.023}$

Using Eq. (17) to predict the test data, in the range $R e=150$ 1000 , the mean absolute error is $3.4 \%$ and the mean error is $2.3 \%$. And in the test range, Eqs. (16) and (17) can predict $90 \%$ of experiment data with the errors within $\pm 15 \%$.

Figure $12 \mathrm{~b}$ gives the detailed comparisons of the friction factor $f$ when correlation equations predicting value and experiment value.

\section{Conclusions}

As for the good thermal hydraulic characters and the compactness, plate-type heat exchangers have been widely applied in waste heat recovery ORC system. The experimental investigation had been done to get thermal hydraulic performance characteristics of the PHE's surface using three different types fluid. The three types of fluid thermal hydraulic characteristics are reported and the empirical correlation are given including three different chevron angles. The main conclusions are,

1. The plate chevron angle has much effects on the thermal hydraulic performance, the heat transfer coefficient $\mathrm{Nu}$ and friction factor $f$ will increase with chevron angle increasing.

2. To overall evaluated enhanced heat transfer for three types of corrugated PHE's surface, the evaluation method of pump power and heat transfer coefficient is applied. And the bigger chevron angle surface has better overall enhanced heat transfer performance.

3. The dimensionless empirical correlation for heat transfer $N u$ and friction factor $f$ is given. In the test range, the calculation mean absolute errors are 9.7 and $6.8 \%$, respectively. And for the $90 \%$ test data, the predict error of the empirical equations is in the $\pm 15 \%$ range.

Open Access This article is distributed under the terms of the Creative Commons Attribution 4.0 International License (http://creativecomm ons.org/licenses/by/4.0/), which permits unrestricted use, distribution, and reproduction in any medium, provided you give appropriate credit to the original author(s) and the source, provide a link to the Creative Commons license, and indicate if changes were made.

\section{References}

1. Qiu, G.; Liu, H.; Riffat, S.: Expander for micro-CHP systems with organic Rankine cycle. Appl. Therm. Eng. 31, 3301-3307 (2011)

2. Bao, J.; Zhao, L.: A review of working fluid and expander selections for organic Rankine cycle. Renew. Sustain. Energy Rev. 24, 325342 (2013)

3. Declaye, S.; Quoilin, S.: Experimental study on an open-drive scroll expander integrated into an ORC (Organic Rankine cycle) system with R245fa as working fluid. Energy 55, 173-183 (2013)

4. Yu, G.; Shu, G.; Tian, H.: Simulation and thermodynamic analysis of bottoming organic Rankine cycle (ORC) of diesel engine (DE). Energy 51, 281-290 (2013)

5. Dolz, V.; Novella, R.; Garcia, A.: HD diesel engine equipped with a bottoming Rankine cycle as a waste heat recovery system. Part1: study and analysis of the waste heat energy. Appl. Therm. Eng. 36, 269-278 (2012)

6. Dong, J.; Wang, J.; Zhang, R.: The organic Rankine cycle development for heavy duty diesel engine. In: Proceedings of the SAEChina Congress 2014: Selected Papers, pp. 139-147. Springer, Berlin (2015) 
7. Focke, W.W.; Zacharides, J.; Oliver, I.: The effect of the corrugation inclination angle on the thermohy draulic performance of plate heat exchangers. Int. J. Heat Mass Transf. 28, 1469-1479 (1985)

8. Khan, T.S.; Khan, M.S.; Chyu, M.C.: Experiment investigation of single phase convective heat transfer coefficient in a corrugated plate heat exchanger for multiple plate configuration. Appl. Therm. Eng. 30, 1058-1065 (2010)

9. Gherasima, I.; Tawsb, M.; Galanisa, N.: Heat transfer and fluid flow in a plate heat exchanger part I. Exp. Investig. Int. J. Therm. Sci. 50, 1492-1498 (2011)

10. Longo, G.A.; Gasparella, A.: Refrigerant R134a vaporization heat transfer and pressure drop inside a small brazed plate heat exchanger. Int. J. Refrigeration 30, 821-830 (2007)

11. Muley, A.; Manglik, R.M.: Experimental study of turbulent flow heat transfer and pressure drop in a plate heat exchanger. J. Heat Transf. 121, 110-117 (1999)
12. Dong, J.; Zhang, X.; Wang, J.: Experimental investigation on heat transfer characteristics of plat heat exchanger applied in organic Rankine cycle (ORC). Appl. Therm. Eng. 112, 1137-1152 (2017)

13. Longo, G.A.: Heat transfer and pressure drop during HFC refrigerant saturated vapor condensation inside a brazed plate heat exchanger. Int. J. Heat Mass Transf. 53, 1079-1087 (2010)

14. Sahiti, N.; Durst, F.: Heat transfer enhancement by pin elements. Int. J. Heat Mass Transf. 48, 4738-4747 (2005)

15. Moffat, R.J.: Describing the uncertainties in experimental results. Exp. Therm. Fluid Sci. 1, 3-17 (1998)

16. Wei, W.M.; Sheen, P.J.: Heat transfer and friction characteristics of fin-and-tube heat exchangers. Int. J. Heat Mass Transf. 43, 16511659 (2000) 